\title{
Correction to: Simultaneous multiprocessing in a software-defined heterogeneous FPGA
}

\author{
Jose Nunez-Yanez $^{1}$ - Sam Amiri ${ }^{1}$ - Mohammad Hosseinabady ${ }^{1}$. \\ Andrés Rodríguez $^{2}$ - Rafael Asenjo ${ }^{2}$ - Angeles Navarro ${ }^{2}$ - Dario Suarez ${ }^{3}$. \\ Ruben Gran ${ }^{3}$
}

\section{Correction to: J Supercomput https://doi.org/10.1007/s11227-018-2367-9}

The presentation of Table 2 was incorrect in the original article. The correct Table 2 is given below. The original article has been corrected.

The original article can be found online at https://doi.org/10.1007/s11227-018-2367-9.

Sam Amiri

ma17215@bristol.ac.uk

Jose Nunez-Yanez

j.l.nunez-yanez@bristol.ac.uk

Mohammad Hosseinabady

m.hosseinabady@bristol.ac.uk

Andrés Rodríguez

andres@ac.uma.es

Rafael Asenjo

asenjo@ac.uma.es

Angeles Navarro

angeles@ac.uma.es

Dario Suarez

dario@unizar.es

Ruben Gran

rgran@unizar.es

1 University of Bristol, Bristol, UK

2 Universidad de Málaga, Málaga, Spain

3 Universidad de Zaragoza, Zaragoza, Spain 
Table 2 Energy change when the second CPU core is utilised

\begin{tabular}{|c|c|c|c|c|}
\hline & $\operatorname{AES}(\%)$ & HotSpot (\%) & $\operatorname{GEMM}(\%)$ & Nbody (\%) \\
\hline $\begin{array}{l}\text { Dynamic with } \\
\text { interrupt }\end{array}$ & -7.73 & +22.93 & -1.52 & -1.64 \\
\hline $\begin{array}{l}\text { Dynamic without } \\
\text { interrupt }\end{array}$ & -1.53 & +2.14 & +13.64 & +11.67 \\
\hline $\begin{array}{l}\text { LogFit with } \\
\text { interrupt }\end{array}$ & -19.51 & +16.54 & +2.87 & +6.89 \\
\hline $\begin{array}{l}\text { LogFit without } \\
\text { interrupt }\end{array}$ & +16.00 & +10.16 & +1.12 & +7.59 \\
\hline
\end{tabular}

Negative values indicate improvement in energy consumption. The lower the better

Open Access This article is distributed under the terms of the Creative Commons Attribution 4.0 International License (http://creativecommons.org/licenses/by/4.0/), which permits unrestricted use, distribution, and reproduction in any medium, provided you give appropriate credit to the original author(s) and the source, provide a link to the Creative Commons license, and indicate if changes were made. 